\title{
The SCARE 2020 Guideline: Updating Consensus Surgical CAse REport (SCARE) Guidelines
}

\section{Riaz A Agha}

Department of Plastic Surgery, Barts Health NHS Trust, London, United Kingdom

Thomas Franchi *

The Medical School, The University of Sheffield, Sheffield, United Kingdom

Catrin Sohrabi

Barts and The London School of Medicine and Dentistry, Queen Mary University of London, London, United Kingdom

Ginimol Mathew

The York Hospital, York Teaching Hospital NHS Foundation Trust, York, United Kingdom

\section{Ahmed Kerwan}

Department of Surgery, Lister Hospital, East and North Hertfordshire NHS Trust, Stevenage, United Kingdom

for the SCARE Group

(members listed at end of paper)

\section{* Corresponding author:}

Mr Thomas Franchi MSc FHEA MAcadMEd

The Medical School, The University of Sheffield

Beech Hill Road, S10 2RX, Sheffield, United Kingdom

Email Address: tpffranchi1@sheffield.ac.uk 
Provenance and Peer Review: Not commissioned, internally reviewed.

Ethical Approval: Not applicable.

Funding: None.

Conflicts of Interest: None declared - the authors have no financial, consultative, institutional, and other relationships that might lead to bias or conflict of interest.

Research Registration: Not applicable.

Author Contribution: RAA: Concept and design, data interpretation and analysis, drafting, revision and approval of final manuscript. TF, CS, GM, AK: Design, data collection, data interpretation and analysis, drafting, revision and approval of final manuscript.

Guarantor: Riaz A Agha. 


\section{Highlights:}

- This was a DELPHI consensus exercise to update the SCARE guidelines.

- Of the invited surgical experts, 53 (98\%) completed the survey. There was a high level of agreement within the SCARE Group.

- The survey responses were incorporated as modifications, and an improved SCARE Checklist is now presented for use. 


\title{
The SCARE 2018 Statement: Updating Consensus Surgical CAse REport (SCARE) Guidelines
}

\begin{abstract}
Introduction: The SCARE Guidelines were first published in 2016 and were last updated in 2018. They provide a structure for reporting surgical case reports and are used and endorsed by authors, journal editors and reviewers, in order to increase robustness and transparency in reporting surgical cases. They must be kept up to date in order to drive forwards reporting quality. As such, we have updated these guidelines via a DELPHI consensus exercise.
\end{abstract}

Methods: The updated guidelines were produced via a DELPHI consensus exercise. Members were invited from the previous DELPHI group, as well as editorial board member and peer reviewers of the International Journal of Surgery Case Reports. The expert group completed an online survey to indicate their agreement with proposed changes to the checklist items.

Results: 54 surgical experts agreed to participate and 53 (98\%) completed the survey. The responses and suggested modifications were incorporated to the 2018 guideline. There was a high degree of agreement amongst the SCARE Group, with all SCARE Items receiving over $70 \%$ scores $7-9$.

Conclusion: A DELPHI consensus exercise was completed, and an updated and improved SCARE Checklist is now presented. 


\section{The SCARE 2020 Statement: Updating Consensus Surgical CAse REport (SCARE) Guidelines}

\section{Introduction}

The SCARE Guidelines were initially published in 2016 and were the first surgical case report guidelines developed through a DELPHI consensus exercise. ${ }^{1}$ They were updated in 2018, ${ }^{2}$ and have now been cited over 3,000 times as they have been utilised by authors submitting case reports to a number of journals. ${ }^{3}$ The guidelines were also listed on the EQUATOR Network website and have been endorsed by multiple journals. The value of the guidelines was underscored by follow-up work that demonstrated their importance in improving the reporting quality of surgical case reports. ${ }^{4}$ In the two years since their last update, we have received feedback on the guidelines from users. Here, we update the guidelines through a new DELPHI consensus exercise.

\section{Methods}

The same DELPHI methodology was utilised as per the original guideline. ${ }^{5}$ Members from the last DELPHI group were invited to participate again but additional individuals were invited to participate to help increase the depth and breadth of the group. Such people were drawn from the editorial board and reviewer base of the International Journal of Surgery Case Reports, a key supporter of the guidelines and where they have been implemented as a mandatory requirement for submission. Potential contributors were contacted by email and the survey was distributed using Google Forms. Members scored the suggested changes on a scale from 1 (strongly disagree) to 9 (strongly agree). As per the previous update, consensus was defined as greater than $70 \%$ agreement (scoring between 7 and 9) for an item change. If this was not reached, the item would remain unchanged.

\section{Results}

In total, 54 people agreed to participate and 53 (98\%) completed the DELPHI survey. A summary of the scores is shown below (Table 1), which demonstrate greater than $70 \%$ agreement on all items. Following this, the revised SCARE guidelines are shown (Table 2). 
Table 1: SCARE 2020 DELPHI scores. Items listed correspond to individual sections of SCARE. Scores ranged from 1 (strongly disagree) to 9 (strongly agree).

\begin{tabular}{|c|c|c|c|}
\hline Item & $1-3(\%)$ & 4-6 (\%) & $7-9(\%)$ \\
\hline 1 & 9.5 & 7.6 & 83.0 \\
\hline 2 & 5.7 & 5.7 & 88.7 \\
\hline $3 a$ & 0.0 & 13.2 & 86.8 \\
\hline $3 b$ & 7.6 & 17.0 & 75.5 \\
\hline $3 c$ & 1.9 & 7.6 & 90.6 \\
\hline $3 d$ & 1.9 & 7.6 & 90.6 \\
\hline $3 e$ & 5.7 & 11.4 & 83.0 \\
\hline 4 & 0.0 & 11.3 & 88.6 \\
\hline $5 a$ & 5.7 & 17.0 & 77.3 \\
\hline $5 b$ & 1.9 & 18.8 & 79.2 \\
\hline $5 c$ & 3.8 & 15.1 & 81.1 \\
\hline $5 d$ & 3.8 & 22.6 & 73.6 \\
\hline $5 e$ & 5.7 & 22.6 & 71.7 \\
\hline 6 & 7.6 & 13.2 & 79.3 \\
\hline 7 & 1.9 & 11.3 & 86.8 \\
\hline $8 a$ & 0.0 & 17.0 & 83.0 \\
\hline $8 b$ & 3.8 & 16.9 & 79.3 \\
\hline $8 c$ & 1.9 & 17.0 & 81.1 \\
\hline $8 d$ & 5.7 & 11.4 & 83.0 \\
\hline $9 a$ & 1.9 & 15.1 & 83.1 \\
\hline $9 b$ & 0.0 & 13.2 & 86.8 \\
\hline $9 c$ & 3.8 & 5.7 & 90.6 \\
\hline $9 d$ & 1.9 & 7.5 & 90.6 \\
\hline $9 e$ & 1.9 & 11.3 & 86.8 \\
\hline $10 a$ & 0.0 & 3.8 & 96.2 \\
\hline $10 \mathrm{~b}$ & 3.8 & 13.2 & 83.0 \\
\hline $10 c$ & 0.0 & 11.3 & 88.7 \\
\hline $10 d$ & 0.0 & 9.4 & 90.6 \\
\hline $11 a$ & 3.8 & 18.9 & 77.4 \\
\hline $11 b$ & 1.9 & 11.3 & 86.8 \\
\hline $11 c$ & 1.9 & 5.7 & 92.4 \\
\hline 11d & 5.7 & 17.0 & 77.4 \\
\hline $11 e$ & 3.8 & 9.4 & 86.8 \\
\hline 12 & 7.5 & 20.8 & 71.7 \\
\hline 13 & 3.8 & 11.3 & 84.9 \\
\hline 14 & 3.8 & 7.5 & 88.7 \\
\hline 15 & 3.8 & 3.8 & 92.5 \\
\hline 16 & 1.9 & 11.3 & 86.8 \\
\hline
\end{tabular}


Table 2: The full revised SCARE 2020 Checklist.

\section{SCARE 2020 Checklist}

Topic

Item Checklist Item Description

\begin{tabular}{|c|c|c|}
\hline Title & 1 & $\begin{array}{l}\text { - The words 'case report' should appear in the title. The title } \\
\text { should also describe the area of focus (e.g. presentation, } \\
\text { patient population, diagnosis, surgical intervention or } \\
\text { outcome). }\end{array}$ \\
\hline Key Words & 2 & $\begin{array}{l}\text { - Include three to six keywords that identify what is covered } \\
\text { in the case report (e.g. patient population, diagnosis or } \\
\text { surgical intervention). } \\
\text { - Include 'case report' as one of the keywords. }\end{array}$ \\
\hline \multirow[t]{5}{*}{ Abstract } & $3 a$ & $\begin{array}{l}\text { Introduction and Importance } \\
\text { - Describe what is important, unique or educational about } \\
\text { the case, and what does this add to the surgical } \\
\text { literature. }\end{array}$ \\
\hline & $3 b$ & $\begin{array}{l}\text { Case Presentation } \\
\text { - Presenting complaints, clinical and demographic details, } \\
\text { and the patient's main concerns. }\end{array}$ \\
\hline & $3 c$ & $\begin{array}{l}\text { Clinical Findings and Investigations } \\
\begin{array}{l}\text { - Clinical findings, investigations performed, main } \\
\text { differentials, and subsequent diagnosis. }\end{array}\end{array}$ \\
\hline & $3 d$ & $\begin{array}{l}\text { Interventions and Outcome } \\
\text { - Describe the rationale for choosing the intervention. } \\
\text { - Describe what was the end result. }\end{array}$ \\
\hline & $3 e$ & $\begin{array}{l}\text { Relevance and Impact } \\
\text { - Describe the main take-away lessons or potential } \\
\text { implications for clinical practice (minimum of three). }\end{array}$ \\
\hline
\end{tabular}




\begin{tabular}{|c|c|c|}
\hline Introduction & 4 & $\begin{array}{l}\text { Background } \\
\text { - Describe briefly the area of focus and the relevant } \\
\text { background contextual knowledge. } \\
\text { Rationale } \\
\text { - Describe why the case is different to what is already } \\
\text { known and why it is important to report? } \\
\text { - Is the case rare or interesting for the specific healthcare } \\
\text { setting, population or country, or is it applicable globally? } \\
\text { Guidelines and Literature } \\
\text { - Give reference to relevant surgical literature and current } \\
\text { standards of care, including any specific guidelines. }\end{array}$ \\
\hline \multirow[t]{5}{*}{$\begin{array}{l}\text { Patient } \\
\text { Information }\end{array}$} & $5 a$ & $\begin{array}{l}\text { Demographic Details } \\
\text { - Include de-identified demographic details of the patient } \\
\text { (e.g. age, sex, ethnicity, occupation). } \\
\text { - Where possible, include other useful pertinent information } \\
\text { (e.g. body mass index, hand dominance, income, level of } \\
\text { education, marital status). }\end{array}$ \\
\hline & $5 b$ & $\begin{array}{l}\text { Presentation } \\
\text { - Describe the patient's presenting complaint. } \\
\text { - Include a collateral account of the history if relevant. } \\
\text { - Describe the patient's mode of presentation (e.g. self- } \\
\text { presentation, ambulance or referred by family physician } \\
\text { or other hospital clinicians). }\end{array}$ \\
\hline & $5 c$ & $\begin{array}{l}\text { Past Medical and Surgical History } \\
\text { - Include any previous interventions and relevant } \\
\text { outcomes. }\end{array}$ \\
\hline & $5 d$ & $\begin{array}{l}\text { Drug History and Allergies } \\
\begin{array}{l}\text { - Specify any acute, repeat, and discontinued medications. } \\
\text { - Include any allergies and/or adverse reactions. }\end{array}\end{array}$ \\
\hline & $5 e$ & $\begin{array}{l}\text { Family History } \\
\text { - Health information regarding first-degree relatives, } \\
\text { specifying any inheritable conditions. }\end{array}$ \\
\hline
\end{tabular}




\begin{tabular}{|c|c|c|}
\hline & & $\begin{array}{l}\text { Social History } \\
\text { - Indicate smoking, alcohol, and recreational drug use. } \\
\text { - Level of social independence, driving status, and type of } \\
\text { accommodation. } \\
\text { Review of Systems } \\
\text { - If appropriate, report on any other information gathered } \\
\text { outside of the focused history. }\end{array}$ \\
\hline $\begin{array}{l}\text { Clinical } \\
\text { Findings }\end{array}$ & 6 & $\begin{array}{l}\text { Describe the general and significant clinical findings } \\
\text { based on initial inspection and physical examination. }\end{array}$ \\
\hline Timeline & 7 & $\begin{array}{l}\text { - Summarise the sequence of events leading up to the } \\
\text { patient's presentation. } \\
\text { - Delays from presentation to diagnosis and/or } \\
\text { intervention should be reported. } \\
\text { - Use tables or figures to illustrate the timeline of events if } \\
\text { needed. }\end{array}$ \\
\hline \multirow[t]{4}{*}{$\begin{array}{l}\text { Diagnostic } \\
\text { Assessment } \\
\text { and } \\
\text { Interpretation }\end{array}$} & $8 a$ & $\begin{array}{l}\text { Diagnostic Assessment } \\
\begin{array}{l}\text { - } \\
\text { Bedside (e.g. urinalysis, electrocardiography, } \\
\text { echocardiography). } \\
\text { - } \quad \text { Laboratory (e.g. biochemistry, haematology, } \\
\text { immunology, microbiology, histopathology). } \\
\text { - } \text { Imaging (e.g. ultrasound, X-ray, CT/MRI/PET). } \\
\text { - Invasive (e.g. endoscopy, biopsy). }\end{array}\end{array}$ \\
\hline & $8 b$ & $\begin{array}{l}\text { Diagnostic Challenges } \\
\text { - Where applicable, describe what was challenging about } \\
\text { the diagnoses (e.g. access, financial, cultural). }\end{array}$ \\
\hline & $8 c$ & $\begin{array}{l}\text { Diagnostic Reasoning } \\
\text { - Describe the differential diagnoses, why they were } \\
\text { considered, and why they were excluded. }\end{array}$ \\
\hline & $8 d$ & $\begin{array}{l}\text { Prognostic Characteristics } \\
\quad-\quad \text { Include where applicable (e.g. tumour staging). }\end{array}$ \\
\hline Intervention & $9 a$ & Pre-Operative Patient Optimisation \\
\hline
\end{tabular}




\begin{tabular}{|c|c|}
\hline & $\begin{array}{l}\text { - } \quad \text { Lifestyle (e.g. weight loss). } \\
\text { - } \text { Medical (e.g. medication review, treating any relevant } \\
\text { pre-existing medical concerns). } \\
\text { - } \quad \text { Procedural (e.g. nil by mouth, enema). } \\
\text { - }\end{array}$ \\
\hline $9 b$ & $\begin{array}{l}\text { Surgical Interventions } \\
\text { - Describe the type(s) of intervention(s) used (e.g. } \\
\text { pharmacological, surgical, physiotherapy, psychological, } \\
\text { preventative). } \\
\text { - Describe any concurrent treatments (e.g. antibiotics, } \\
\text { analgesia, antiemetics, venous thromboembolism } \\
\text { prophylaxis). } \\
\text { - Medical devices should have manufacturer and model } \\
\text { specifically mentioned. }\end{array}$ \\
\hline $9 c$ & $\begin{array}{l}\text { Specific Details regarding Interventions } \\
\text { - Describe the rationale behind the treatment offered, how } \\
\text { it was performed and time to intervention. } \\
\text { - For surgery, include details on the intervention (e.g. } \\
\text { anaesthesia, patient position, preparation used, use of } \\
\text { other relevant equipment, sutures, devices, surgical } \\
\text { stage). } \\
\text { - The degree of novelty for a surgical technique/device } \\
\text { should be mentioned (e.g. 'first in human'). } \\
\text { - For pharmacological therapies, include information on } \\
\text { the formulation, dosage, strength, route, and duration. }\end{array}$ \\
\hline $9 d$ & $\begin{array}{l}\text { Operator Details and Setting of Intervention } \\
\text { - Where applicable, include operator experience and } \\
\text { position on the learning curve, prior relevant training, } \\
\text { and specialisation (e.g. 'junior trainee with } 3 \text { years of } \\
\text { surgical specialty training'). }\end{array}$ \\
\hline
\end{tabular}




\begin{tabular}{|c|c|c|}
\hline & & $\begin{array}{l}\text { Specify the setting in which the intervention was } \\
\text { performed (e.g. district general hospital, major trauma } \\
\text { centre). }\end{array}$ \\
\hline & $9 e$ & $\begin{array}{l}\text { Deviation from Initial Management Plan } \\
\text { - State if there were any changes in the planned } \\
\text { intervention(s), and describe these alongside the } \\
\text { rationale (e.g. delays to intervention). }\end{array}$ \\
\hline \multirow[t]{3}{*}{$\begin{array}{l}\text { Follow-Up } \\
\text { and } \\
\text { Outcomes }\end{array}$} & $10 a$ & $\begin{array}{l}\text { Specify Details regarding the Follow-Up } \\
\text { - When (e.g. how long after discharge, frequency, } \\
\text { maximum follow-up length at time of submission). } \\
\text { - Where (e.g. home via video consultation, primary care, } \\
\text { secondary care). } \\
\text { - How (e.g. telephone consultation, clinical examination, } \\
\text { blood tests, imaging). } \\
\text { - Any specific long-term surveillance requirements (e.g. } \\
\text { imaging surveillance of endovascular aneurysm repair or } \\
\text { clinical exam/ultrasound of regional lymph nodes for skin } \\
\text { cancer). } \\
\text { - Any specific post-operative instructions (e.g. post- } \\
\text { operative medications, targeted physiotherapy, } \\
\text { psychological therapy). }\end{array}$ \\
\hline & $10 \mathrm{~b}$ & $\begin{array}{l}\text { Intervention Adherence and Compliance } \\
\text { - Where relevant, detail how well the patient adhered to } \\
\text { and tolerated the advice provided (e.g. avoiding heavy } \\
\text { lifting for abdominal surgery, or tolerance of } \\
\text { chemotherapy and pharmacological agents). } \\
\text { - Explain how adherence and tolerance were measured. }\end{array}$ \\
\hline & $10 c$ & $\begin{array}{l}\text { Outcomes } \\
\text { - Expected versus attained clinical outcome as assessed } \\
\text { by the clinician. Reference literature used to inform } \\
\text { expected outcomes. }\end{array}$ \\
\hline
\end{tabular}




\begin{tabular}{|c|c|c|}
\hline & & $\begin{array}{l}\text { - When appropriate, include patient-reported measures } \\
\text { (e.g. questionnaires including quality-of-life scales). }\end{array}$ \\
\hline & $10 \mathrm{~d}$ & $\begin{array}{l}\text { Complications and Adverse Events } \\
\text { - Precautionary measures taken to prevent complications } \\
\text { (e.g. antibiotic or venous thromboembolism prophylaxis). } \\
\text { - All complications and adverse or unanticipated events } \\
\text { should be described in detail and ideally categorised in } \\
\text { accordance with the Clavien-Dindo Classification (e.g. } \\
\text { blood loss, length of operative time, wound complications, } \\
\text { re-exploration or revision surgery). } \\
\text { - If relevant, was the complication reported to the relevant } \\
\text { national agency or pharmaceutical company. } \\
\text { - Specify the duration of time between completion of the } \\
\text { intervention and discharge, and whether this was within } \\
\text { the expected timeframe (if not, why not). } \\
\text { - Where applicable, the 30-day post-operative and long- } \\
\text { term morbidity/mortality may need to be specified. } \\
\text { - State if there were no complications or adverse } \\
\text { outcomes. }\end{array}$ \\
\hline \multirow[t]{3}{*}{ Discussion } & $11 a$ & $\begin{array}{l}\text { Strengths } \\
\text { - Describe the relevant strengths of the case. } \\
\text { - Detail any multidisciplinary or cross-speciality relevance. }\end{array}$ \\
\hline & $11 b$ & $\begin{array}{l}\text { Weaknesses and Limitations } \\
\text { - Describe the relevant weaknesses or limitations of the } \\
\text { case. } \\
\text { - For novel techniques or devices, outline any } \\
\text { contraindications and alternatives, potential risks and } \\
\text { possible complications if applied to a larger population. }\end{array}$ \\
\hline & $11 \mathrm{c}$ & $\begin{array}{l}\text { Relevant Literature } \\
\text { - Include a discussion of the relevant literature and, if } \\
\text { appropriate, similar published cases. }\end{array}$ \\
\hline
\end{tabular}




\begin{tabular}{|c|c|c|}
\hline & & $\begin{array}{l}\text { - Describe the implications for clinical practice guidelines } \\
\text { and any relevant hypotheses generated. }\end{array}$ \\
\hline & $11 d$ & $\begin{array}{l}\text { - Provide a rationale for the conclusions drawn from the } \\
\text { case. }\end{array}$ \\
\hline & $11 e$ & $\begin{array}{l}\text { Take-Away Lessons } \\
\text { - Outline the key clinical lessons from this case report. } \\
\text { - Discuss any differences in approach to diagnosis or } \\
\text { patient management which the authors might adopt in } \\
\text { future similar cases, based on their experience of the } \\
\text { case. }\end{array}$ \\
\hline $\begin{array}{l}\text { Patient } \\
\text { Perspective }\end{array}$ & 12 & $\begin{array}{l}\text { - Where appropriate, the patient should be given the } \\
\text { opportunity to share their perspective on the } \\
\text { intervention(s) they received (e.g. sharing quotes from a } \\
\text { consented and anonymised interview). }\end{array}$ \\
\hline $\begin{array}{l}\text { Informed } \\
\text { Consent }\end{array}$ & 13 & $\begin{array}{l}\text { - The authors must provide evidence of consent, where } \\
\text { applicable, and if requested by the Journal. } \\
\text { - State the method of consent at the end of the article (e.g. } \\
\text { verbal or written). } \\
\text { - If not provided by the patient, explain why (e.g. death of } \\
\text { patient and consent provided by next of kin). If the patient } \\
\text { or family members were untraceable then document the } \\
\text { tracing efforts undertaken. }\end{array}$ \\
\hline $\begin{array}{l}\text { Additional } \\
\text { Information }\end{array}$ & 14 & $\begin{array}{l}\text { - Please state any author contributions, acknowledgments, } \\
\text { conflicts of interest, sources of funding, and where } \\
\text { required, institutional review board or ethical committee } \\
\text { approval. } \\
\text { - Disclose whether the case has been presented at a } \\
\text { conference or regional meeting. }\end{array}$ \\
\hline $\begin{array}{l}\text { Clinical } \\
\text { Images and } \\
\text { Videos }\end{array}$ & 15 & $\begin{array}{l}\text { - Where relevant and available, include clinical images to } \\
\text { help demonstrate the case pre-, peri-, and post- } \\
\text { intervention (e.g. radiological, histopathological, patient } \\
\text { photographs, intraoperative images). }\end{array}$ \\
\hline
\end{tabular}




\begin{tabular}{|l|l|l|l|}
\hline & & $\begin{array}{l}\text { Where relevant and available, include a link (e.g. Google } \\
\text { Drive, YouTube) to the narrated operative video can be } \\
\text { included to highlight specific techniques or operative } \\
\text { findings. } \\
\text { - Ensure all media files are appropriately captioned and } \\
\text { indicate points of interest to allow for easy interpretation. }\end{array}$ \\
\hline Referencing & 16 & $\begin{array}{l}\text { Include reference to the SCARE } 2020 \text { publication by } \\
\text { stating: 'This case report has been reported in line with } \\
\text { the SCARE Criteria [include citation]' at the end of the } \\
\text { introductory section. }\end{array}$ & \\
\hline
\end{tabular}

\section{Discussion}

The SCARE guidelines have provided a useful guidance to those writing case reports. Previous research on their implementation has found a statistically significant $10 \%$ increase in reporting completeness when utilized. ${ }^{4}$

Surgical journals have been slow to take up reporting guidelines. We have previously shown how the majority (62\%) of the 193 surgical journals listed in the surgery category in the Journal Citation Report 2014, made no mention of reporting guidelines within their guide for authors at all. ${ }^{6}$

This update to the SCARE guidelines will help further improve the reporting quality of case reports and we encourage authors, reviewers, editors and journals to adopt them. Authors should cite the guidelines in their methods section and upload a completed check list of compliance for reviewers and editors to inspect. Such checklists will be provided in a variety of formats for easy usage on the SCARE website (https://www.scareguideline.com).

\section{Conclusion}

Updated SCARE 2020 guidelines are presented which should now be implemented by authors, reviewers, editors and journals with the aim of improving reporting quality. 


\section{References}

1. Agha RA, Fowler AJ, Saetta A, Barai I, Rajmohan S, Orgill DP, for the SCARE Group. The SCARE guidelines: Consensus-based surgical case report guidelines. Int J Surg. 2016;34:180-186.

2. Agha RA, Borrelli MR, Farwana R, Koshy K, Fowler AJ, Orgill DP, for the SCARE Group. The SCARE 2018 statement: Updating consensus Surgical CAse REport (SCARE) guidelines. Int J Surg. 2018;60:132-136.

3. Google Scholar. The SCARE statement: Consensus-based surgical case report guidelines [Online]. Available from: https://scholar.google.com/citations?hl=en\&view op=list works\&gmla=AJsNF5uNrz1s3076sn7pC Qvbw4VoF4DBs65x0C IZ4CcOeGdTp4G9fs kxNvMR Arn 1U9HaamKh0pll3AkPyYu9BclaOFaGy 25R7sKSMwS5DGraGSn8M\&us er=lg4IUDEAAAAJ\#d=gs md citad\&u=\%2Fcitations\%3Fview op\%3Dview citation\%26hl\%3Den\%26user\%3DI g4IUDEAAAAJ\%26citation for view\%3DIg4IUDEAAAAJ\%3AWA5NYHcadZ8 C\%26tzom\%3D0 [Accessed 25 October 2020].

4. Agha RA, Farwana R, Borrelli MR, Kusu-Orkar T, Millip MC, Thavayogan R, Garner J, Tickunas T, Orgill DP. Impact of SCARE Guideline on the reporting of surgical case reports: A before and after study. International Journal of Surgery $2017 ; 45: 144-148$.

5. Pill J. The Delphi method: Substance, context, a critique and an annotated bibliography. Soc Econ Plann Sci. 1971;5:57-71.

6. Agha RA, Barai I, Rajmohan S, Lee S, Anwar MO, Fowler AJ, Orgill DP, Altman DG. Support for reporting guidelines in surgical journals needs improvement: A systematic review. Int J Surg. 2017;45:14-17. 
SCARE Group Members (collaborative authors):

- Achilles Thoma - McMaster University, Canada

- Andrew J Beamish - Swansea University Medical School, United Kingdom

- Ashraf Noureldin - Almana Hospital Khobar, Saudi Arabia

- Ashwini Rao - MCODS Mangalore/ Manipal Academy of Higher Education, India

- Baskaran Vasudevan - MIOT Hospital, India

- Ben Challacombe - Guy's and St Thomas' NHS Foundation Trust, United Kingdom

- Benjamin Perakath - Dr Gray's Hospital, United Kingdom

- Boris Kirshtein - Rabin MC, Israel

- Burcin Ekser - Indiana University School of Medicine, United States

- C S Pramesh - Tata Memorial Centre, India

- Daniel M Laskin - Virginia Commonwealth University Schools of Dentistry and Medicine, United States

- David Machado-Aranda - University of Michigan. United States

- Diana Miguel - Cuf Descobertas Hospital, Portugal

- Duilio Pagano - IRCCS-ISMETT/UPMC, Italy

- Frederick H Millham - Harvard University, United States

- Gaurav Roy - Sir Ganga Ram Hospital, India

- Huseyin Kadioglu - BHT Clinic, Turkey

- lain J Nixon - NHS Lothian/University of Edinburgh, United Kingdom

- Indraneil Mukhejree - Staten Island University Hospital/Zucker School of Medicine, United States

- James A McCaul - Queen Elizabeth University Hospital, United Kingdom

- James Chi-Yong Ngu - Changi General Hospital, Singapore

- Joerg Albrecht - Cook County Health/Rush Medical College, United States

- Juan Gomez Rivas - La Paz University Hospital, Spain

- Kandiah Raveendran - Fatimah Hospital, Malaysia

- Laura Derbyshire - Manchester University NHS Foundation Trust, United Kingdom

- M Hammad Ather - Aga Khan University, Pakistan 
- Mangesh A Thorat - Guy's Hospital/King's College London/Queen Mary University of London, United Kingdom

- Michele Valmasoni - Padova University Hospital, Italy

- Mohammad Bashashati - Texas Tech University Health Sciences Center, United States

- Mushtaq Chalkoo - Government Medical College Srinagar, India

- Nan Zun Teo - Changi General Hospital, Singapore

- Nicholas Raison - King's College London, United Kingdom

- Oliver J Muensterer - Dr von Hauner Children's Hospital/University of Munich, Germany

- Patrick James Bradley - Nottingham University Hospitals, United Kingdom

- Prabudh Goel - All India Institute of Medical Sciences, New Delhi, India

- Prathamesh S Pai - Tata Memorial Hospital/Homi Bhabha National Institute, India

- Raafat Yahia Afifi - Cairo University, Egypt

- Richard David Rosin - University of The West Indies, Barbados

- Roberto Coppola - Campus Bio-Medico University School of Medicine, Italy

- Roberto Klappenbach - Hospital Simplemente Evita, Argentina

- Rolf Wynn- UiT The Arctic University of Norway/ University Hospital of North Norway, Norway

- Rudy Leon De Wilde - Carl von Ossietzky University of Oldenburg, Germany

- Salim Surani - Texas A\&M University, United States

- Salvatore Giordano - Turku University Hospital, Finland

- Samuele Massarut - CRO Aviano National Cancer Institute IRCCS, Italy

- Shahzad G Raja - Harefield Hospital, United Kingdom

- Somprakas Basu - All India Institute of Medical Sciences Rishikesh, India

- Syed Ather Enam - Aga Khan University, Pakistan

- Todd Galvin Manning - Austin Health, Australia

- Trent Cross - Mater Hospital, Australia

- Veena KL Karanth - Kasturba Medical College and Hospital, India

- Veeru Kasivisvanathan - University College London, United Kingdom

- Zubing Mei - Shuguang Hospital/Shanghai University of Traditional Chinese Medicine, China 